\title{
Development of flexible zein-wax composite and zein-fatty acid blend films for controlled release of lysozyme
}

\author{
Iskender Arcan, Ahmet Yemenicioğlu* \\ Department of Food Engineering, Faculty of Engineering, Izmir Institute of Technology, 35430, Gülbahçe Köyü, Urla, Izmir, Turkey
}

\section{A R T I C L E I N F O}

Article history:

Received 19 September 2012

Accepted 5 December 2012

\section{Keywords:}

Zein

Composite

Blend

Lysozyme

Catechin

Controlled release

\begin{abstract}
A B S T R A C T
The aim of this study was controlled release of lysozyme by modification of hydrophobicity and morphology of zein films using composite and blend film making methods. The incorporation of beeswax, carnauba or candelilla wax into films at $5 \%(\mathrm{w} / \mathrm{w})$ of zein gave composite films containing amorphous wax particles, while incorporation of oleic acid into film at $5 \%$ of zein caused formation of blend films containing many spherical zein capsules within their matrix. The lysozyme release rates of composites reduced as the melting point of waxes increased. The composites and blends showed 2.5 to 17 fold lower lysozyme release rates than controls. The films were effectively plasticized by using catechin. The catechin also provided antioxidant activity of films (up to $69 \mu \mathrm{mol}$ Trolox $/ \mathrm{cm}^{2}$ ) and contributed to their controlled release properties by reducing film porosity. The films showed antimicrobial activity against Listeria innocua. This work showed the possibility of obtaining advanced edible films having flexibility, antimicrobial and antioxidant activity and controlled release properties.
\end{abstract}

(c) 2012 Elsevier Ltd. All rights reserved.

\section{Introduction}

There has been a growing interest to develop the functional properties of packaging materials and to obtain packed foods with better shelf-life and quality. Active packaging incorporating antimicrobials is one of the most promising areas since application of this method can improve safety of foods by inhibiting pathogenic bacteria or controlling spoilage flora using minimum amounts of active compounds (Appendini \& Hotchkiss, 2002). Although different natural and chemical preservatives have successfully been incorporated into plastic, biodegradable and/or edible packaging materials, health concerns of the consumers and environmental problems caused a particular interest in using natural antimicrobial compounds in edible packaging materials (Appendini \& Hotchkiss, 2002; Han, 2005).

The natural antimicrobial agents frequently employed in active packaging include antimicrobial enzymes, bacteriocins, essential oils and phenolic compounds (Appendini \& Hotchkiss, 2002; Joerger, 2007; Mastromatteo, Mastromatteo, Conte, \& Del Nobile, 2010). Lysozyme obtained from hen egg white is one of the most potential candidates for antimicrobial packaging since it has a GRAS status and it shows good stability and activity in different films and food systems under refrigerated storage temperatures (Mecitoglu et al., 2006; Ünalan, Korel, \& Yemenicioğlu, 2011). Thus, lysozyme has recently been tested extensively in different plastic materials such as cellulose acetate, nylon, and PVOH (Gemili, Yemenicioglu, \& Altinkaya, 2009; Joerger, 2007) and

\footnotetext{
* Corresponding author. Tel.: +90 232 7506292; fax: +90 2327506196.

E-mail address: ahmetyemenicioglu@iyte.edu.tr (A. Yemenicioğlu).
}

biopolymeric materials from zein, soy protein, carrageenan, whey protein, chitosan, alginate and pullulan (Joerger, 2007; Mendes de Souza, Fernández, López-Carballo, Gavara, \& Hernández-Muñoz, 2010). This enzyme shows antimicrobial activity mainly on Gram-positive bacteria by splitting the bonds between $\mathrm{N}$-acetylmuramic acid and $\mathrm{N}$-acetylglucosamine of the peptidoglycan in their cell walls. However, due to their protective outer membrane surrounding the peptidoglycan layer, it does not show antibacterial activity against Gram-negative bacteria. Thus, the application of lysozyme in active packaging targets mainly inhibition of the critical Gram-positive pathogenic bacteria such as Listeria monocytogenes (Duan, Park, Daeschel, \& Zhao, 2007; Min, Harris, Han, \& Krochta, 2005). However, when lysozyme is combined with ethylenediaminetetraacetic acid (EDTA), the outer membranes of Gram-negative bacteria are destabilized by EDTA and the obtained films become effective on the other critical pathogenic bacteria including Escherichia coli 0157:H7 and Salmonella typhimurium (Gucbilmez, Yemenicioglu, \& Arslanoglu, 2007; Mecitoglu et al., 2006; Padgett, Han, \& Dawson, 1998; Ünalan et al., 2011).

Antimicrobial packaging targets mainly the food surface on which microbiological changes occur most intensively (Appendini \& Hotchkiss, 2002). However, a sufficient antimicrobial effect could not be achieved unless the release rate of antimicrobial compounds from the packaging materials to food surface could be adjusted considering the physical and chemical properties of food, growth kinetics of target pathogenic or spoilage microorganisms and the expected food shelf life (Han, 2005). In the literature, there are different studies which aim to design plastic, biodegradable or edible films particularly for controlled release of lysozyme. Buonocore, Conte, Corbo, Sinigaglia, and Del Nobile (2005) 
produced multilayered PVOH films or changed the degree of crosslinking for PVOH films to achieve controlled release of lysozyme. To achieve controlled release of lysozyme, Gemili et al. (2009) developed asymmetric cellulose acetate films with varying porosities while Bezemer et al. (2000) changed composition and molecular weight of copolymers in biodegradable polyethylene glycerol/poly butylene trephthalate films. Mendes de Souza et al. (2010) developed sodium caseinate films of which lysozyme release profiles could be changed by modifying $\mathrm{pH}$ and the amount of crosslinking agents such as $\mathrm{CaCl}_{2}$, transglutaminase and glyoxal used in film making. Park, Daeschel, and Zhao (2004) formed chitosan-lysozyme composites and achieved different release rates for lysozyme by changing amount of enzyme within the composite structure. Gucbilmez et al. (2007) achieved a sustained lysozyme release from zein films by forming their composites with chickpea proteins.

Zein, a water insoluble hydrophobic storage protein found in corn and maize, attracts a particular interest as a biopolymer since it has excellent film forming and gas barrier properties; it is one of the rare proteins soluble in various organic solvents including ethanol and it is the major co-product of the oil and rapidly growing bioethanol industries (Manley \& Evans, 1943; Selling, Woods, Sessa, \& Biswas, 2008; Shukla \& Cheryan, 2001; Wang et al., 2007; Zhang, Luo, \& Wang, 2011). Thus, a particular interest has been focused on use of zein in active food packaging by incorporation of different natural antimicrobials including lysozyme (Gucbilmez et al., 2007; Mecitoglu et al., 2006; Padgett et al., 1998). However, the classical brittleness, and flexibility problems of zein films is a great limitation for their use as a free standing film and more widespread application as an active coating material. Moreover, to increase the potential application of active zein based films in food industry further studies are needed to develop smart controlled release mechanisms for different natural antimicrobial agents used in active packaging. Recently, Arcan and Yemenicioglu (2011) improved the flexibility of zein films effectively by using natural phenolic compounds like catechin, but studies to develop smart controlled release mechanisms for lysozyme containing zein films are scarce. In the present study, controlled release of lysozyme was achieved by exploiting the different morphologies of zein-wax composites and zein-oleic acid blends prepared by means of homogenization in presence of emulsifier lecithin. The classical brittleness problem of the obtained zeinbased films was also eliminated by using the recently discovered natural zein plasticizer catechin (Arcan \& Yemenicioglu, 2011). This study brings a novel approach by showing possibility of creating flexible active packaging with controlled release properties using an edible biopolymer.

\section{Materials and methods}

\subsection{Materials}

Maize zein (batch number: $058 \mathrm{K0093),} \mathrm{(+)-catechin} \mathrm{hydrate}$ ( $\geq 98 \%$ ), Micrococcus lysodeikticus, carnauba wax (No.1, refined), beeswax, candelilla wax, and oleic acid (90\%) were from Sigma Chem. Co. (St. Louise, Mo, USA). Soybean L- $\alpha$-lecithin and glycerol were from Merck (Darmsdadt, Germany). All other chemicals were reagent grade. Fresh hen eggs used in production of lysozyme were obtained from a supermarket in Izmir (Turkey).

\subsection{Preparation of films}

Zein films were produced as described in Padgett et al. (1998). Briefly, $1.4 \mathrm{~g}$ zein was dissolved with $8.1 \mathrm{~mL}$ of ethanol (96\%) by mixing slowly with a magnetic stirrer for $25 \mathrm{~min}$. Glycerol $(0.4 \mathrm{~mL})$ was then added to the medium as a plasticizer. The temperature of the mixture was then increased until it started to boil. The mixing was ceased and the solution was cooled to the room temperature after it had been boiled for $5 \mathrm{~min}$. After that, the lysozyme $(11.7 \mathrm{mg} / \mathrm{g}$ film forming solution) used as antimicrobial agent, catechin (50-100 mg/g film forming solution) used as an additional plasticizer for the zein (Arcan \& Yemenicioglu, 2011) and lecithin (5\% (w/w) of zein) used as emulsifier (for wax and oleic acid containing films only) were added into film forming solutions and the mixtures were homogenized (Heidolph, Germany, rotor $\Phi=6.6 \mathrm{~mm}$ tip) at 10,000 rpm for $4 \mathrm{~min}$. Then, $4.3 \mathrm{~g}$ portions of the homogenized film forming solutions were poured into the glass templates $(\mathrm{W} \times \mathrm{L} \times \mathrm{H}: 8.5 \times 8.5 \times 0.4 \mathrm{~cm})$ and dried for $19 \pm$ $2 \mathrm{~h}$ at $25{ }^{\circ} \mathrm{C}$ in an incubator unless otherwise was stated (see Section 2.6). This procedure was also used to obtain zein-wax composite and zein-fatty acid blend films by adding waxes (carnauba wax, candelilla wax and beeswax) or fatty acid (oleic acid) into film forming solutions at $5 \%(\mathrm{w} / \mathrm{w})$ of zein. The waxes were added just before initiation of heating to melt them during boiling and ease their homogenization, while oleic acid was added after the boiling step following cooling to room temperature.

\subsection{Production of lysozyme}

Lysozyme was produced according to the method previously applied by Mecitoglu et al. (2006). For this purpose, carefully separated egg whites were diluted 3-fold with $0.05 \mathrm{M} \mathrm{NaCl}$ solution. To precipitate the egg white proteins other than the lysozyme, the $\mathrm{pH}$ of this mixture was set to 4.0 by adding several drops of $1 \mathrm{~N}$ acetic acid, and the solution was diluted with equal volume of $60 \%(\mathrm{v} / \mathrm{v})$ ethanol. After $6 \mathrm{~h}$ incubation at room temperature in the presence of $30 \%$ ethanol, the mixture was centrifuged at $15.000 \times \mathrm{g}$ for $15 \mathrm{~min}$ at $4{ }^{\circ} \mathrm{C}$ and the precipitate was discarded. The supernatant containing lysozyme was first dialyzed for $21 \mathrm{~h}$ at $4{ }^{\circ} \mathrm{C}$ by three changes of $2000 \mathrm{~mL}$ distilled water and then lyophilized by using a freeze drier (Labconco, FreeZone, 6 liter, Kansas City, MO, USA). The lyophilized enzyme was stored at $-18{ }^{\circ} \mathrm{C}$ until it was used in film making.

\subsection{Release tests and lysozyme activity}

The release tests of films were conducted in water at $4{ }^{\circ} \mathrm{C}$ by applying shaking during the incubation period. Briefly, $4 \times 4 \mathrm{~cm}$ pieces of films were placed into glass Petri dishes containing $50 \mathrm{~mL}$ of deionized water. The dishes were kept at $4{ }^{\circ} \mathrm{C}$ in an incubator and shaken with an orbital shaker working at $80 \mathrm{rpm}$. The release tests were conducted until equilibrium was reached for release of lysozyme or an insignificant increase was observed in lysozyme release. The lysozyme activity was monitored by taking $0.1 \mathrm{~mL}(\times 3)$ aliquots from the release test solution at different time intervals. The enzyme activities in collected aliquots were determined spectrophotometrically at $660 \mathrm{~nm}$ by using a Shimadzu (Model 2450, Japan) spectrophotometer equipped with a constant temperature cell holder working at $30^{\circ} \mathrm{C}$. The enzyme activities were calculated from the slopes of initial linear portions of absorbance vs. time curves and expressed as unit (U) which was defined as 0.001 change in absorbance in $1 \mathrm{~min}$. All calculations were corrected by considering the activity removed by collected aliquots during sampling. The total lysozyme activity released from each film corresponded to maximum units released per $\mathrm{cm}^{2}$ of the films $\left(\mathrm{U} / \mathrm{cm}^{2}\right)$ at the equilibrium. All activity measurements were conducted for three times. The release curves were formed by plotting calculated released activities $\left(\mathrm{U} / \mathrm{cm}^{2}\right)$ vs. time $(\mathrm{h})$. The initial release rates of lysozyme were determined from the slope of the initial linear portion of release curve. The release rates were expressed as $\mathrm{U} / \mathrm{cm}^{2} / \mathrm{h}$.

\subsection{Scanning electron microscopy (SEM) of films}

The cross-sectional morphology of selected films was determined by using SEM (Philips XL 30S FEG, FEI Company, Netherlands) under high vacuum mode at an operating voltage varying between 2 and $6 \mathrm{kV}$. Films were prepared for SEM by crashing, following freezing 
in liquid nitrogen. Then samples were gold coated with a sputter coater (Emitech K550X, Quorum Technologies Inc.,UK) under $15 \mathrm{~mA}$ for $60 \mathrm{~s}$. The thickness of the films was measured from SEM crosssectional views of films by using Scandium software (Olympus Soft Imaging Solutions GmbH, Münster, Germany).

\subsection{Mechanical properties of films}

Tensile strength at break, elongation at break, and elastic modulus were determined using a Texture Analyser TA-XT2 (Stable Microsystems, Godalming, UK) according to ASTM Standard Method D 882-02 (ASTM, 2002). For conditioning of the films used in mechanical testing, the standard drying period of $19 \mathrm{~h}$ was extended to $48 \mathrm{~h}$ at $25{ }^{\circ} \mathrm{C}$. Moreover, for these films only, the drying was conducted at 50\% RH using a controlled test cabinet (TK 120, Nüve, Turkey). Films were cut into $5 \mathrm{~mm}$ wide and $80 \mathrm{~mm}$ length strips. The initial grip distance was $50 \mathrm{~mm}$ and crosshead speed was $50 \mathrm{~mm} / \mathrm{min}$. At least seven replicates of each film were tested.

\subsection{Fourier Transform Infrared (FTIR) analyses of films}

For the FTIR analysis, the zein films were placed on the horizontal attenuated total reflectance sampling accessory (ZnSe crystal plate) of a FTIR spectrometer equipped with DTGS detector (Spectrum 100 Instrument, Perkin-Elmer Inc., Wellesley, MA). FTIR spectra of the samples were recorded between 4000 and $650 \mathrm{~cm}^{-1}$. Interferograms were averaged for 32 scans at $4 \mathrm{~cm}^{-1}$ resolution. The background spectrum was automatically subtracted from the spectra of the samples. For each film, the averaged spectrum of the nine different scans $(n=9)$, was used for further data analysis. Spectrum software (Perkin-Elmer) was used for all data analysis. The spectra were interactively baselined from two arbitrarily selected points. Finally, the spectra were normalized in specific regions for comparison of the films.

\subsection{Soluble catechin content and antioxidant capacity of films}

To determine the soluble catechin content of films release experiments were conducted in water as described in Section 2.4. The catechin concentration was monitored in release medium until it reached the equilibrium concentration for the released phenolic compound. The catechin concentration was determined spectrophotometrically at $510 \mathrm{~nm}$ according to the colorimetric method of Meyers, Watkins, Pritts, and Liu (2003) developed for quantification of flavonoids. The total soluble catechin concentrations released from the films were expressed as mg catechin per $\mathrm{cm}^{2}$ of the films $\left(\mathrm{mg} / \mathrm{cm}^{2}\right)$ using the calibration curve prepared by catechin. All concentration measurements were conducted for three times. The antioxidant capacity of the films was based on calculating the trolox equivalent antioxidant capacity (TEAC) of their soluble catechin content. The TEAC of catechin was determined by using spectrophotometric ABTS radical cation decolorazation assay conducted at $734 \mathrm{~nm}$ (Re et al., 1999). The results were expressed as $\mu \mathrm{mol}$ Trolox equivalents released per $\mathrm{cm}^{2}$ of films ( $\mu \mathrm{mol}$ Trolox $/ \mathrm{cm}^{2}$ ).

\subsection{Antimicrobial potential of films}

The antimicrobial potentials of the films were tested against Listeria innocua (NRRL B-33314; supplied from USDA, Microbial Genomics and Bioprocessing Research Unit, Peoria, IL, USA) as a test microorganism. For antimicrobial tests, 18 discs $(1.3 \mathrm{~cm}$ in diameter) from each film were prepared by a cork borer. Total of 15 discs were selected randomly and 3 discs were placed into each Petri dish containing nutrient agar which had been previously inoculated with $0.1 \mathrm{~mL}$ cell culture. The inocula of microorganisms were prepared in peptone water $(0.1 \%)$ by using $48 \mathrm{~h}$ culture grown in nutrient agar, and the cell concentration was set to $1.0 \mathrm{McF}$ arland unit (corresponded to $13 \times 10^{7} \mathrm{CFU} / \mathrm{mL}$ ). The
Petri dishes were firstly incubated at $+4{ }^{\circ} \mathrm{C}$ for $4 \mathrm{~h}$ to prevent rapid diffusion of the lysozyme and then secondly they were incubated at $37{ }^{\circ} \mathrm{C}$ for $36 \mathrm{~h}$ for microbial development. The diameter of the zones formed was measured by using a calliper. The results were expressed as average zone areas $\left(\mathrm{mm}^{2}\right)$.

\subsection{Statistical analysis}

Analysis of variance (ANOVA) was applied using Minitab 15 (Minitab Inc., State College, PA, USA) to determine the effects of film compositions on antimicrobial potentials and mechanical properties of the films. Multiple comparisons of means were performed using Fisher's least significant difference (LSD) method with a significance threshold of $P<0.05$.

\section{Results and discussion}

\subsection{Controlled release properties of films}

3.1.1. Effects of plasticizer catechin on lysozyme release profiles of films Arcan and Yemenicioglu (2011) have recently found that some phenolic compounds including catechin can be used effectively as natural plasticizer for zein films which has commercialization problems as self-standing films due to their brittleness and lack of flexibility. The interaction of hydroxyl groups of phenolic compounds with carbonyl groups of zein biopolymer creates a plasticizing effect and causes modifications in film morphology depending on the molecular properties of phenolic compounds (Alkan et al., 2011; Arcan \& Yemenicioglu, 2011). The major morphological change caused by catechin in zein films is the reduced film porosity (Arcan \& Yemenicioglu, 2011). Thus, effects of catechin induced morphological changes in lysozyme release profiles of zein films was determined before evaluating the lysozyme release profiles of developed composite and blend films. The release tests were conducted by using films with $0.7 \mathrm{mg} / \mathrm{cm}^{2}$ lysozyme since zein films containing the indicated amount of enzyme produced by the same method had been effective on different bacteria and successfully used in a food application (Gucbilmez et al., 2007; Ünalan et al., 2011). Fig. 1A shows that the lysozyme release from catechin plasticized zein films was much slower than those of control zein films. The initial release rates of 3 and $4.5 \mathrm{mg} / \mathrm{cm}^{2}$ catechin containing films were almost 2.5 fold lower than those of control films, while films containing catechin at $6 \mathrm{mg} / \mathrm{cm}^{2}$ showed almost 4 fold lower initial release rate than the control films (Table 1 ). These results clearly showed the effect of catechin on lysozyme release profiles and supported the previous findings of Arcan and Yemenicioglu (2011) who reported reduced porosity of zein films by incorporation of catechin. On the other hand, the similar total amounts of lysozyme activity released from control films and different catechin containing films at equilibrium showed the lack of enzyme trapping by possible catechin induced morphological changes (Table 1). This result also showed the lack of any considerable modifications in lysozyme activity due to its possible interactions with the catechin.

\subsubsection{Lysozyme release profiles of zein-wax composite films}

It is well known that the release mechanism of many films are effected from polymer swelling occurred as a result of diffusion of water molecules into the polymeric film matrix (Mastromatteo et al., 2010). Therefore, it is commonly accepted that the incorporation of hydrophobic compounds into films retards their hydration and subsequent diffusion of active agents from their film matrix (Ouattara, Simard, Piette, Begin, \& Holley, 2000; Ozdemir \& Floros, 2003). Thus, to further slow down the release rate of lysozyme the hydrophobicity of catechin plasticized films was increased by incorporating carnauba wax (CAR) into film forming solutions by means of homogenization in presence of lecithin emulsifier. The distribution of hydrophobic wax particles within the film matrix aimed not only to increase hydrophobicity 
A

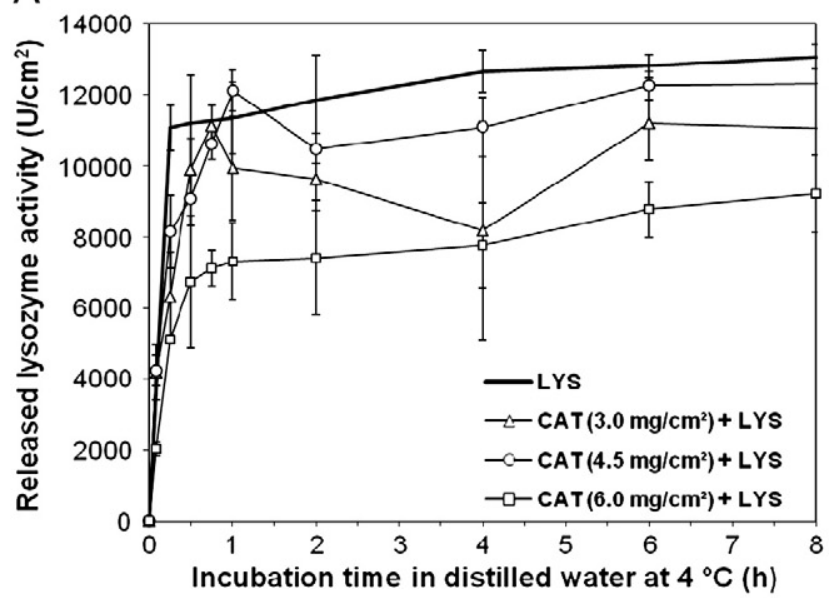

B
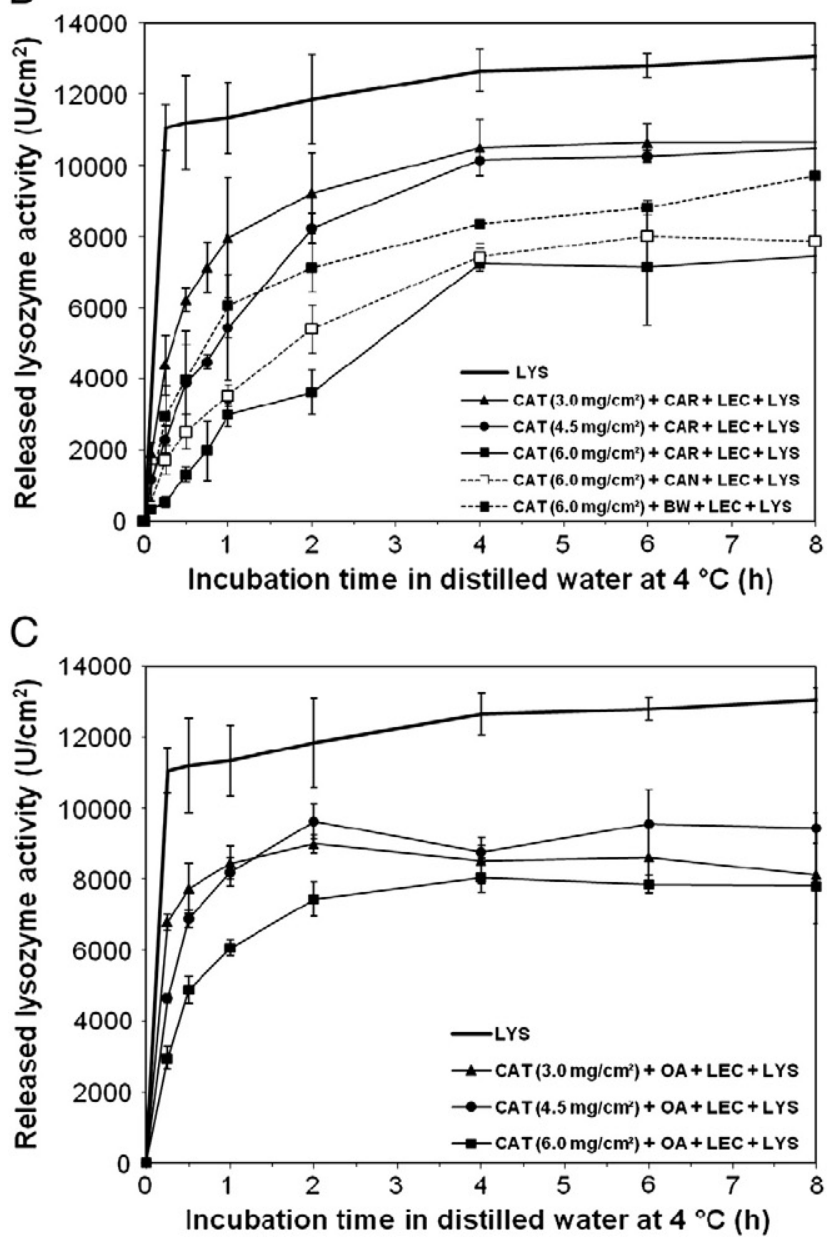

Fig. 1. Release profiles of lysozyme from catechin plasticized zein (A); zein-wax composite (B); and zein-oleic acid blend (C) films. (lysozyme concentration: $0.7 \mathrm{mg} / \mathrm{cm}^{2}$; wax, oleic acid, and lecithin concentrations: $5 \%(\mathrm{w} / \mathrm{w})$ of zein; CAT: catechin, LYS: lysozyme, CAN: candelilla wax, CAR: carnauba wax, BW: beeswax, OA: oleic acid, LEC: lechitin).

of the films but also to increase the film tortuosity (Ozdemir \& Floros, 2003). Fig. 1B shows that the lysozyme release from catechin incorporated zein-CAR composite films was much slower than those of catechin plasticized control zein films. In fact, for $6 \mathrm{mg} / \mathrm{cm}^{2}$ catechin containing zein-CAR composite films, the initial release rate of lysozyme is almost 4 and 17 fold lower than those of similar amount of catechin containing zein film and control zein film, respectively. Similar to the catechin containing zein films, the increase of catechin concentration in zein-
CAR composites reduced the lysozyme release rate effectively. This result clearly showed the effectiveness of barriers formed against lysozyme diffusion when carnauba wax and catechin were used in film making. It seemed that the increased hydrophobicity and tortuosity of films caused by carnauba wax and reduced porosity of films caused by catechin is responsible for the effective reduction in lysozyme release rates.

The use of waxes with different melting points (MP) was also tested to evaluate possibility of creating further modifications in morphology and change lysozyme release profiles of composite films (Fig. 1B). The formation of composite film by candelilla wax (CAN) (MP: $68.5-72.5{ }^{\circ} \mathrm{C}$ ) instead of CAR (MP: $82-86{ }^{\circ} \mathrm{C}$ ) did not considerably change the release profiles of lysozyme, but the initial lysozyme release rate of zein-CAN films was almost 1.5 fold higher than those of zein-CAR film (Table 1). Moreover, the lysozyme release rate also increased considerably when beeswax (BW) (MP: 62-66 ${ }^{\circ} \mathrm{C}$ ) was used in composites instead of CAN and CAR. These results clearly showed the increased lysozyme release rates from zein-wax composite films as the MP of wax reduced. This was expected since lower MP of waxes increased the efficiency of mixing and homogenization of zein with the wax and this reduced the film tortuosity which is provided with the dispersed wax particles. On the other hand, it is worth to note that the formation of zein-wax composites did not cause a considerable lysozyme trapping within the films. In zeinCAR and zein-BW composites the released activity at the equilibrium reached 92 and $89 \%$ of that for control film, respectively while activity released from zein-CAN composite films reached $77 \%$ of that for control film.

\subsubsection{Lysozyme release profiles of zein-oleic acid blend films}

Not only waxes but also fatty acids, acetylated monoglycerides and essential oils were used to modify hydrophobicity and morphology of films and change their release profiles for the active compounds (Ouattara et al., 2000). Thus, in this study the lysozyme release profiles of blends formed by homogenization of zein with oleic acid in the presence of lecithin emulsifier were also investigated. Fig. 1C shows that the lysozyme release rates of zein-OA blends plasticized with 4.5 and $6 \mathrm{mg} / \mathrm{cm}^{2}$ catechin were 1.6-1.7 and 4.5-6.3 folds lower than those of zein films plasticized with same amounts of catechin and that of unplasticized control zein film, respectively. However, zein-OA blends and zein films containing $3 \mathrm{mg} / \mathrm{cm}^{2}$ catechin showed similar lysozyme release rates. This result revealed that the catechin has a concentration dependent critical role in formation of morphological changes important for the controlled release properties of films. On the other hand, release tests also showed that zein-OA blend films were less effective on decreasing initial lysozyme release rate than zein-CAR composite films. At the single plasticizer concentration of $6 \mathrm{mg} / \mathrm{cm}^{2}$ catechin, zein-OA blends were also less effective than zeinCAN composites to slow down lysozyme release rates, but zein-OA blends and zein-BW composites gave similar lysozyme release rates at the indicated catechin concentration.

\subsection{Characteristics of films}

\subsubsection{SEM analyses of zein films}

The SEM images of the developed films were obtained to understand the morphological changes in films occurred by plasticization with catechin and formation of composite and blend structures. As seen in Fig. 2A to C, the incorporation of catechin into zein films reduced the porosity of films and gave denser films at a concentration dependant manner. This result was in line with the previous findings of Arcan and Yemenicioglu (2011) and it clearly explained the reduced release rate of lysozyme in catechin containing films. It is also important to report the formation of some 1 to $3 \mu \mathrm{m}$ sized particles and aggregates within films containing $6 \mathrm{mg} / \mathrm{cm}^{2}$ catechin (Fig. 2C). These particles and aggregates formed within the films increased 
Table 1

Total soluble lysozyme activity and catechin concentrations, and some kinetic parameters determined from release curves.

\begin{tabular}{|c|c|c|c|c|c|c|c|}
\hline \multicolumn{4}{|c|}{ Film composition } & \multirow{2}{*}{$\begin{array}{l}\text { Initial lysozyme release } \\
\text { rate }\left(\mathrm{U} / \mathrm{cm}^{2} / \mathrm{h}\right)\end{array}$} & \multirow{2}{*}{$\begin{array}{l}\text { Total released lysozyme } \\
\text { activity }\left(\mathrm{U} / \mathrm{cm}^{2}\right)\end{array}$} & \multirow{2}{*}{$\begin{array}{l}\text { Total released catechin } \\
\left(\mathrm{mg} / \mathrm{cm}^{2}\right)\end{array}$} & \multirow{2}{*}{$\begin{array}{l}\text { Antioxidant potential } \\
\left(\mu \mathrm{mol} \text { Trolox } / \mathrm{cm}^{2}\right)^{\mathrm{b}}\end{array}$} \\
\hline $\begin{array}{l}\text { Catechin } \\
\left(\mathrm{mg} / \mathrm{cm}^{2}\right)\end{array}$ & $\begin{array}{l}\text { Lysozyme } \\
\left(\mathrm{mg} / \mathrm{cm}^{2}\right)\end{array}$ & $\begin{array}{l}\text { Wax or oleic } \\
\text { acid }(\%)^{\mathrm{a}}\end{array}$ & $\begin{array}{l}\text { Lecithin } \\
(\%)^{\mathrm{a}}\end{array}$ & & & & \\
\hline- & 0.7 & - & - & $\begin{array}{l}44,260 \\
(0-0.25)^{\mathrm{c}}\end{array}$ & $\begin{array}{l}12,622 \pm 2098 a^{d} \\
(72)^{e}\end{array}$ & - & - \\
\hline 3.0 & 0.7 & - & - & $\begin{array}{l}17,242 \\
(0-0.75)\end{array}$ & $\begin{array}{l}11,408 \pm 2282 a b \\
(72)\end{array}$ & $1.77 \pm 0.06 b^{d}$ & 28.6 \\
\hline 4.5 & 0.7 & - & - & $\begin{array}{l}16,873 \\
(0-0.75)\end{array}$ & $\begin{array}{l}13,481 \pm 418 b \\
(72)\end{array}$ & $3.02 \pm 0.06 \mathrm{~cd}$ & 48.7 \\
\hline 6.0 & 0.7 & - & - & $\begin{array}{l}11,517 \\
(0-0.75)\end{array}$ & $\begin{array}{l}12,030 \pm 1171 a b \\
(72)\end{array}$ & $3.83 \pm 0.08 \mathrm{e}$ & 61.8 \\
\hline 3.0 & 0.7 & $5(\mathrm{CAR})^{\mathrm{f}}$ & 5 & $\begin{array}{l}11,013 \\
(0-0.75)\end{array}$ & $\begin{array}{l}12,603 \pm 498 a b \\
(48)\end{array}$ & $1.97 \pm 0.05 b$ & 31.8 \\
\hline 4.5 & 0.7 & 5 (CAR) & 5 & $\begin{array}{l}6781 \\
(0-0.75)\end{array}$ & $\begin{array}{l}12,109 \pm 1089 a b \\
(72)\end{array}$ & $3.19 \pm 0.02 \mathrm{~d}$ & 51.5 \\
\hline 6.0 & 0.7 & 5 (CAR) & 5 & $\begin{array}{l}2611 \\
(0-0.75)\end{array}$ & $\begin{array}{l}11,551 \pm 488 \mathrm{ab} \\
(72)\end{array}$ & $4.21 \pm 0.16 f$ & 67.9 \\
\hline 6.0 & 0.7 & 5 (CAN) & 5 & $\begin{array}{l}3982 \\
(0-1)\end{array}$ & $\begin{array}{l}9751 \pm 709 a \\
(72)\end{array}$ & $4.29 \pm 0.08 \mathrm{f}$ & 69.2 \\
\hline 6.0 & 0.7 & $5(\mathrm{BW})$ & 5 & $\begin{array}{l}6702 \\
(0-1)\end{array}$ & $\begin{array}{l}11,184 \pm 714 a b \\
(72)\end{array}$ & $4.28 \pm 0.09 f$ & 69.0 \\
\hline 3.0 & 0.7 & $5(\mathrm{OA})$ & 5 & $\begin{array}{l}17,807 \\
(0-0.5)\end{array}$ & $\begin{array}{l}10,953 \pm 1402 \mathrm{ab} \\
(72)\end{array}$ & $1.09 \pm 0.04 a$ & 17.6 \\
\hline 4.5 & 0.7 & $5(\mathrm{OA})$ & 5 & $\begin{array}{l}9752 \\
(0-1)\end{array}$ & $\begin{array}{l}11,408 \pm 1965 a b \\
(72)\end{array}$ & $1.78 \pm 0.06 b$ & 28.7 \\
\hline 6.0 & 0.7 & $5(\mathrm{OA})$ & 5 & $\begin{array}{l}7040 \\
(0-1)\end{array}$ & $\begin{array}{l}10,012 \pm 425 a \\
(72)\end{array}$ & $2.87 \pm 0.09 c$ & 46.3 \\
\hline
\end{tabular}

a Concentrations of waxes, oleic acid and lecithin as \% of zein $(w / w)$.

b Values are Trolox equivalents of released catechin and do not reflect the antioxidant activity of other released film components which trolox equivalents were $\leq 5 \%$ of that for released catechin.

$c$ Time periods $(\mathrm{h})$ of data used in best fitting curves. $\mathrm{r}^{2}$ of curves were between 0.7093 and 0.989 .

d Different letters in each column show significant difference at $P<0.05$.

e Time (h) at which the equilibrium was reached for lysozyme release.

f CAR: carnauba wax; CAN: candelilla wax; BW: beeswax; OA: oleic acid.

when catechin at $6 \mathrm{mg} / \mathrm{cm}^{2}$ was incorporated with lysozyme at $0.7 \mathrm{mg} / \mathrm{cm}^{2}$ (Fig. 2D). It seemed that these are insoluble lysozyme aggregates, catechin crystals, or other insoluble complexes formed by interaction of different film components. On the other hand, the morphological effects of composite making with different waxes are seen in Fig. 2D to G. The addition of waxes into zein films caused dramatic changes in film morphology and formed some amorphous wax aggregates within the film matrix. These aggregates were observed most intensively in zein-CAR composites (Fig. 2E). The wax aggregates within zein-CAN composites were less intensive than those in zeinCAR composites (Fig. 2F), while BW caused the formation of lowest amount of wax aggregates within the films (Fig. 2G). These observations compared well with our release test results which suggested a relationship between MP of employed waxes and film tortuosity. As indicated at Section 3.1.2, CAR has the highest MP of all three waxes, thus more wax aggregate formation occurred within their composite films. In fact, the aggregation of CAR within heated and cooled film forming solutions was clearly observed in this work during film making studies. However, the CAR aggregates were distributed effectively by high speed homogenization in presence of lecithin. Due to their lower MP, CAN and BW formed little and almost no aggregates following heating and cooling of film forming solutions, respectively. Thus, CAN and BW were more easily distributed within the film making solutions by homogenization and formed less aggregates than CAR within the matrix of final dried composite films. These results showed that the MP of waxes is a critical factor affecting the amount of insoluble wax aggregates within the matrix of composite films. Evaluation of these SEM results together with the release test results suggests that the increased intensity of wax particles is beneficial to increase film tortuosity and to reduce the release rates of lysozyme from the composite films.

On the other hand, Fig. $2 \mathrm{H}$ shows that the addition of oleic acid into zein films caused formation of many spherical capsules within films. The morphological changes of zein structure when it is mixed with oleic acid without use of lecithin emulsifier was recently explained by Wang, Yin, and Padua (2008). According to these authors the morphological changes in zein-oleic acid system occurred at three steps; (1) formation of large numbers of oleic acid coated zein spheres, (2) partial melting of the spheres by means of oleic acid, and (3) transformation of a sponge like morphology by interconnection of spheres with channels and tunnels. The spheres observed by SEM of zein-oleic acid films in this work lacked the interconnections specified by Wang et al. (2008). Thus, it seemed that the lecithin emulsifier used in this work stabilized the oleic acid coating formed around zein spheres. It appears that the repulsion formed by negative charges of lecithin at the oleic acid coating of formed zein spheres prevented the interaction and melting down of these spheres which formed the sponge-like structure described by Wang et al. (2008). Thus, it appeared that the reduced release rates of lysozyme in catechin containing zein-oleic acid blend films are in part due to the entrapment of lysozyme within spherical capsules which increased the barriers against enzyme diffusion.

\subsubsection{Mechanical properties of films}

In order to analyse their mechanical properties tensile strength at break, elongation at break, and Young's modulus values of films were determined (Table 2). The control zein films lacking lysozyme and catechin showed very little elongation, but the tensile strength value of the control films at the breaking point (17.67 MPa) was significantly higher than those of the catechin plasticized films $(0.93-3.23 \mathrm{MPa})$ and composite and blend films $(0.77-1.11 \mathrm{MPa})(P<0.05)$. The addition of lysozyme alone reduced the tensile strength and Young's modulus of zein films significantly $(P<0.05)$, but it did not cause any significant change in film elongation $(P>0.05)$. In contrast, the addition of catechin effectively plasticized zein films and improved their elongation significantly. Similar to the previous report of Arcan and Yemenicioglu (2011), the 


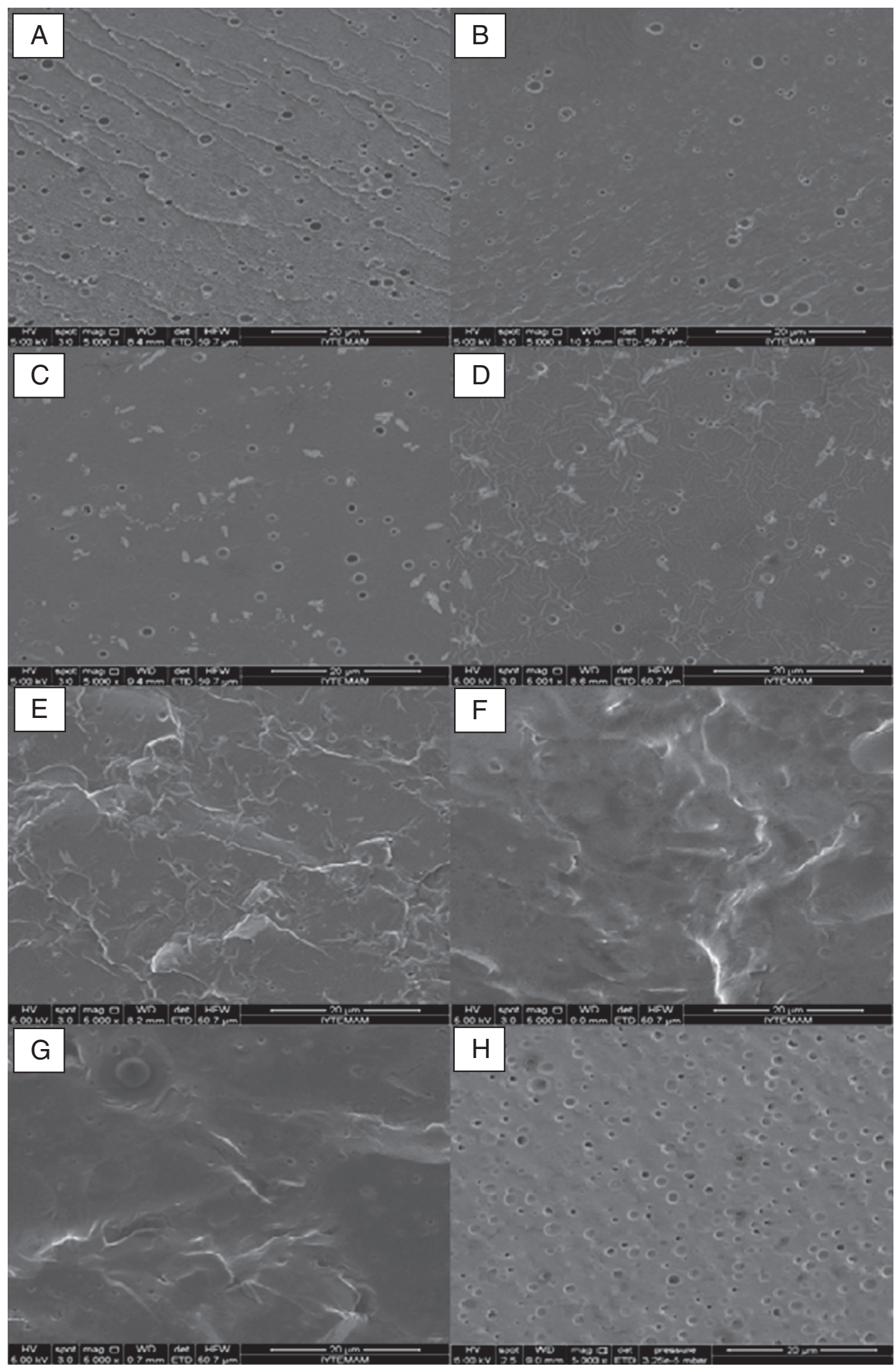

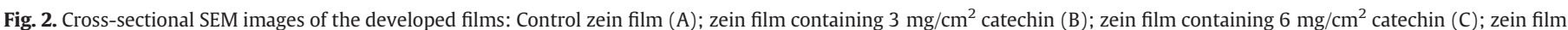

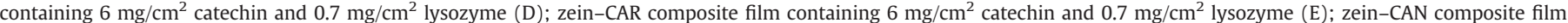

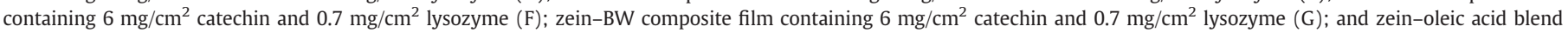
film containing $6 \mathrm{mg} / \mathrm{cm}^{2}$ catechin and $0.7 \mathrm{mg} / \mathrm{cm}^{2}$ lysozyme $(\mathrm{H})$.

plasticizing effect of catechin was concentration dependent since the increase of catechin concentration in zein films from 3 to $6 \mathrm{mg} / \mathrm{cm}^{2}$ increased film elongation almost 5 fold. To understand the possible mechanism of plasticization with catechin, the zein film structure should be discussed in more details. It has been recently shown that the zein films consist of a meshwork which is composed of doughnut 
Table 2

Mechanical properties of zein based composite and blend films.

\begin{tabular}{|c|c|c|c|c|c|c|c|}
\hline \multicolumn{4}{|c|}{ Film compositions } & \multirow{2}{*}{$\begin{array}{l}\text { Tensile strength at } \\
\text { break (MPa) }\end{array}$} & \multirow{2}{*}{$\begin{array}{l}\text { Elongation at } \\
\text { break (\%) }\end{array}$} & \multirow{2}{*}{$\begin{array}{l}\text { Young's modulus } \\
\text { (MPa) }\end{array}$} & \multirow{2}{*}{$\begin{array}{l}\text { Film thickness } \\
(\mu \mathrm{m})\end{array}$} \\
\hline $\begin{array}{l}\text { Catechin } \\
\left(\mathrm{mg} / \mathrm{cm}^{2}\right)\end{array}$ & $\begin{array}{l}\text { Lysozyme } \\
\left(\mathrm{mg} / \mathrm{cm}^{2}\right)\end{array}$ & $\begin{array}{l}\text { Wax or oleic } \\
\text { acid }(\%)^{\mathrm{a}}\end{array}$ & $\begin{array}{l}\text { Lecithin } \\
(\%)^{\mathrm{a}}\end{array}$ & & & & \\
\hline- & - & - & - & $17.67 \pm 0.93 a^{b}$ & $4 \pm 1 \mathrm{f}$ & $775 \pm 44 a$ & $113 \pm 1$ \\
\hline 3.0 & - & - & - & $3.23 \pm 0.58 c$ & $33 \pm 5 e$ & $167 \pm 40 c$ & $191 \pm 3$ \\
\hline 6.0 & - & - & - & $0.93 \pm 0.20 \mathrm{~d}$ & $172 \pm 23 a$ & $31 \pm 7 d$ & $186 \pm 3$ \\
\hline- & 0.7 & - & - & $13.80 \pm 1.26 b$ & $3 \pm 1 \mathrm{f}$ & $670 \pm 45 b$ & $138 \pm 1$ \\
\hline 6.0 & 0.7 & - & - & $1.02 \pm 0.21 d$ & $136 \pm 26 b$ & $42 \pm 8 d$ & $189 \pm 2$ \\
\hline 6.0 & 0.7 & $5(\mathrm{CAR})^{\mathrm{c}}$ & 5 & $1.11 \pm 0.08 \mathrm{~d}$ & $95 \pm 7 c$ & $66 \pm 6 \mathrm{~d}$ & $176 \pm 2$ \\
\hline 6.0 & 0.7 & $5(\mathrm{CAN})$ & 5 & $0.89 \pm 0.08 d$ & $65 \pm 15 d$ & $56 \pm 6 d$ & $179 \pm 2$ \\
\hline 6.0 & 0.7 & $5(\mathrm{BW})$ & 5 & $0.77 \pm 0.07 d$ & $62 \pm 18 d$ & $39 \pm 9 d$ & $172 \pm 2$ \\
\hline 6.0 & 0.7 & $5(\mathrm{OA})$ & 5 & $0.91 \pm 0.08 \mathrm{~d}$ & $117 \pm 18 b c$ & $46 \pm 4 d$ & $173 \pm 4$ \\
\hline
\end{tabular}

a Concentrations of waxes, oleic acid and lecithin as \% of zein (w/w).

b Different letters in each column show significant difference at $P<0.05$.

c CAR: carnauba wax; CAN: candelilla wax; BW: beeswax; OA: oleic acid.

structures formed by asymmetric rods joined to each other (Guo, Liu, An, Li, \& Hu, 2005). The hydrophobic interactions among asymmetric rods is the primary force which keep them together and maintain the film integrity (Guo et al., 2005), but these interactions are also responsible for the brittleness and lack of flexibility in zein films. It was assumed that the formation of hydrogen bonds between the hydroxyl groups of catechin and the carbonyl group of zein protein formed a week but an elastic film network. Moreover, the increased number of phenolic hydroxyl groups provided with free catechin increased the hydrophilicity of the films. Thus, the hydrophobic interactions are weakened and an elastic network with more mobile zein molecules is formed. This hypothesis is in line with that of Arcan and Yemenicioglu (2011) who showed the plasticizing effect of phenolic compounds such as catechin, gallic acid, p-hydroxy benzoic acid, and ferulic acid on zein. On the other hand, the formation of zein-wax composites and zein-oleic acid blends in presence of lysozyme and catechin caused a significant reduction in film elongation $(P<0.05)$. However, the composites and blend films are still much more flexible than the controls. This result confirmed the recent findings of Alkan et al. (2011) who tested mechanical properties of zein and zein-wax composites containing gallic acid. Fabra, Talens, and Chiralt (2008) also reported reduction in elongation of wax containing caseinate films and attributted this effect to discontinuities in the polymer network by the incorporated waxes. However, it is important to note that the zein-CAR composites and zein-OA blends showed more elongation than zein-CAN and zeinBW composite films. On the other hand, no significant change occurred in tensile strength and Young's modulus values of the films by addition of waxes or oleic acid to form a composite or blend film structure $(P>0.05)$. These results contradicted with Sohail, Wang, Biswas, and Oh (2006) who incorporated paraffin wax into casein-zein hydrolizate films and reported a reduced tensile strength for these composite films. The effects of waxes on tensile strengths of zein films were also different than casein films which showed an increase in their tensile strengths by addition of carnauba or candelilla waxes (Chick \& Hernandez, 2002). These reports showed that the mechanical changes in protein-wax composite structures are complex. It appears that the mechanical changes in composite systems could be highly variable depending on amounts and molecular properties of each constituent in the mixture and degree of their compatibility and interactions within the films.

\subsubsection{FTIR analyses of films}

FTIR spectroscopy was employed to determine the possible hydrogen bond formation in zein films by the effect of plasticizer catechin. The average FTIR spectra of the control film and films containing catechin at different concentrations were given in Fig. 3. It is accepted that the specific regions of the FTIR spectrum representing the characteristic protein bands consisting of amide A $\left(3600-3100 \mathrm{~cm}^{-1}\right)$ originated mainly from $\mathrm{N}-\mathrm{H}$ stretching, while amide I (1750-1600 $\left.\mathrm{cm}^{-1}\right)$ originated mainly from $\mathrm{C}=\mathrm{O}$ stretching, and amide II $\left(1500-1400 \mathrm{~cm}^{-1}\right)$ originated both from $\mathrm{N}-\mathrm{H}$ bending and $\mathrm{C}-\mathrm{N}$ stretching (Barth, 2007). Fig. $3 \mathrm{~A}, \mathrm{~B}$, and $\mathrm{C}$ shows that the bandwidth of the amide $\mathrm{A}$, I, and II regions broadened as the catechin concentration in the film structure increased. In the literature, there are increasing number of reports that the broadening of amide A, I and II bands at the indicated regions was due to hydrogen bond formation between protein and phenolic compounds (Alkan et al., 2011; He et al., 2011; Mohammed-Ziegler \& Billes, 2002; Zou, Li, Percival, Bonard, \& Gu, 2012). Zou et al. (2012) who investigated the interactions of zein with procyanidins attributed the band broadening in amide I and II regions to hydrogen bond formation between zein and the phenolic compounds. He et al. (2011) who worked with collagen films containing procyanidins also reported that band broadening at amide A, amide I and II of film spectra suggested $\mathrm{H}$ bond formation between the collagen and the phenolic compound. On the other hand, band shifting at amide A towards lower wavenumbers could also indicate the hydrogen bond formation (Hasni et al., 2011; Mohammed-Ziegler \& Billes, 2002). In this study, the peak point of amide A region at $3288 \mathrm{~cm}^{-1}$ for the control film shifted down to 3287,3286 , and $3285 \mathrm{~cm}^{-1}$ with the addition of catechin at $1.5,3.0$, and $4.5 \mathrm{mg} / \mathrm{cm}^{2}$, respectively. These results obtained by FTIR analyses suggested the potential roles of H-bonds formed between zein and catechin in dramatic morphological and mechanical changes in catechin plasticized films. However, further studies are needed with model protein and phenolic compounds in less complex systems than films to fully understand the individual contribution of $\mathrm{H}$-bonds and other confounding factors in band shifting and broadening. The studies on possible roles of phenolic - $\mathrm{OH}$ groups in band broadening are particularly needed since phenolic compounds might also give peaks at the amide A, amide I and II regions (Ramos-Tejada et al., 2002; Robb, Geldart, Seelenbinder, \& Brown, 2002).

\subsection{Antioxidant and antimicrobial properties of films}

\subsubsection{Soluble catechin content and antioxidant potential of films}

The test of total flavonoid concentrations in release mediums at different intervals showed the soluble catechin contents of different films (Table 1). In zein films incorporated with 3 to $6 \mathrm{mg} / \mathrm{cm}^{2}$ catechin 59 to $64 \%$ of the catechin existed free and solubilized during the release tests. Thus, the release of soluble catechin on food surface and a resulting antioxidant activity is expected during a potential food application. On the other hand, the remaining catechin within the films was expected to be bound to the film matrix by $\mathrm{H}$ bonds. This hypothesis compares well with previous findings of Alkan et al. (2011) who developped active zein films containing gallic acids and explained zein-gallic acid interaciton with $\mathrm{H}$ bonds formed between these components. The incorporation of waxes increased the soluble catechin content slightly since extremely hydrophobic waxes did not contain hydrogen bonding groups to interact with catechin. In contrast, the soluble catechin content of zein-oleic acid blend films 
A

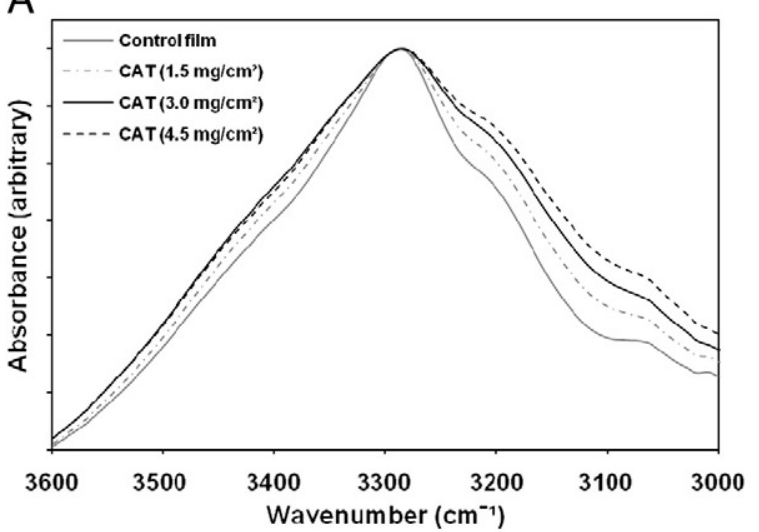

B

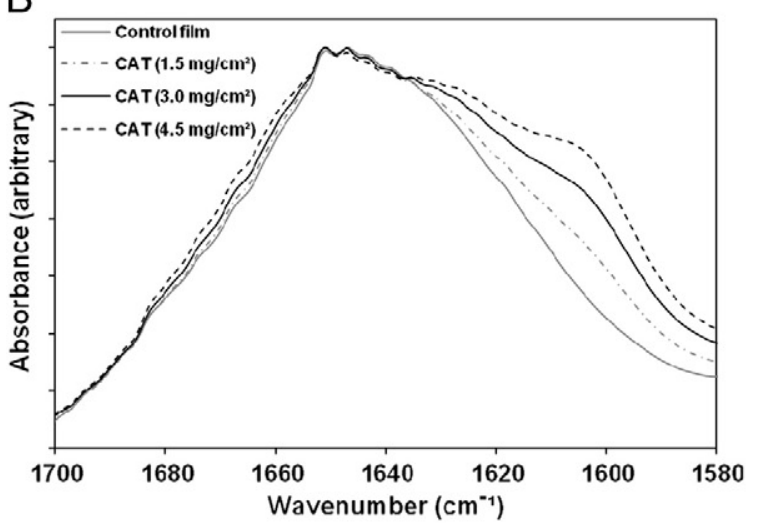

C

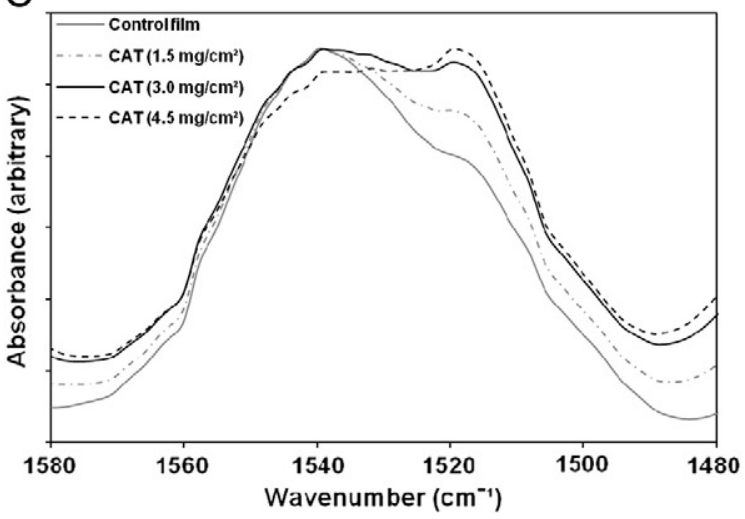

Fig. 3. FTIR spectrum of zein films incorporated with catechin at different concentrations at amide A (A), amide I (B), and amide II (C) spectral regions.

was 1.3 to 1.8 fold lower than those of zein and zein-wax composite films. This result suggested the immobilization of a portion of catechin within the zein-oleic acid film matrix which contained many spherical capsules. Thus, the highest antioxidant potential originated from free soluble catechin was calculated for zein-wax composites followed by zein and zein-oleic acid blend films. Although the release of the considerable portion of catechin from films is an advantage to improve antioxidant and bioactive status of packed foods, this might affect the flexibility of films during storage of actively packed foods. Further studies should be conducted to evaluate mechanical properties of developed films during food applications. However, it is clear that the use of catechin is highly beneficial to improve antioxidant and bioactive status of food and reduce problems associated with brittleness during production, storage and handling of pre-cast films before food application.
Table 3

Antimicrobial potential of zein based composite and blend films.

\begin{tabular}{lllll}
\hline \multicolumn{2}{l}{ Film composition } & & $\begin{array}{l}\text { Average zone area } \\
\left(\mathrm{mm}^{2}\right)\end{array}$ \\
$\begin{array}{lllll}\text { Catechin } \\
\left(\mathrm{mg} / \mathrm{cm}^{2}\right)\end{array}$ & $\begin{array}{l}\text { Lysozyme } \\
\left(\mathrm{mg} / \mathrm{cm}^{2}\right)\end{array}$ & $\begin{array}{l}\text { Wax or oleic } \\
\text { acid }(\%)^{\mathrm{a}}\end{array}$ & $\begin{array}{l}\text { Lecithin } \\
(\%)^{\mathrm{a}}\end{array}$ & \\
\hline- & - & - & - & $\begin{array}{l}\text { *bacterial growth under } \\
\text { the disc }\end{array}$ \\
- & 0.7 & - & - & $119 \pm 26 \mathrm{a}^{\mathrm{b}}$ \\
6.0 & - & - & - & *no bacterial growth \\
& & & & under the disc \\
6.0 & 0.7 & - & - & $115 \pm 23 \mathrm{a}$ \\
6.0 & 0.7 & $5(\mathrm{CAR})^{\mathrm{c}}$ & 5 & $89 \pm 46 \mathrm{a}$ \\
6.0 & 0.7 & $5(\mathrm{CAN})$ & 5 & $90 \pm 10 \mathrm{a}$ \\
6.0 & 0.7 & $5(\mathrm{BW})$ & 5 & $127 \pm 25 \mathrm{a}$ \\
6.0 & 0.7 & $5(\mathrm{OA})$ & 5 & $83 \pm 9 \mathrm{a}$ \\
\hline
\end{tabular}

a Concentrations of waxes, oleic acid and lecithin as \% of zein $(w / w)$.

b Different letters in column show significant difference at $P<0.05$.

c CAR: carnauba wax; CAN: candelilla wax; BW: beeswax; OA: oleic acid.

\subsubsection{Antimicrobial potential of films}

The antimicrobial effects of the developed films were tested on L. innocua by using the classical disc diffusion method. The control zein film without lysozyme and catechin did not form any inhibition zones (Table 3). Moreover, an extensive bacterial growth was observed below control film discs when they were removed carefully from the agar. Although the antimicrobial potential of catechin against L. monocytogenes was reported previously (Ku, Hong, \& Song, 2008), no inhibition zones were observed for the films containing catechin. However, no bacterial growth was observed below catechin containing disks and this indicated a limited antilisterial effect of this phenolic compound at the studied concentration. In contrast, all other films containing lysozyme showed strong antimicrobial effect on L. innocua and formed clear zones around their discs. Although, there are slight differences among their zone area, no significant differences were determined among the antimicrobial performances of zein, zein-wax composite and zein-oleic acid blend films containing lysozyme or lysozyme and catechin $(P>0.05)$. This result confirmed our release tests which did not indicate any significant trapping of lysozyme within the films by composite and blend formation.

\section{Conclusions}

In this work, the flexible zein-wax composites and the zein-fatty acid blend films were developed for controlled release of lysozyme. The controlled release properties obtained were attributed to multiple factors including increased hydrophobicity of films, morphological changes in films formed by composite and blend film making and the reduced pore sizes of films by the plasticizer catechin. In composites the lysozyme release rates reduced as the melting point of the wax used was increased and as films got more tortuous with the aggregated wax particles. On the other hand, the morphological changes affecting the controlled release properties of zein-oleic acid blend films were related to the formation of extensive spherical zein capsules which increased the diffusion barriers for lysozyme. In both composites and blends the effectiveness of morphological changes on lysozyme diffusion rate increased by the increased concentration of catechin which reduces the film porosity. The catechin also effectively plasticized zein films and provided an antioxidant potential to the developed films. The results of this work showed the possibility of producing flexible antimicrobial and antioxidant films with controlled release properties by using zein which is the major by-product of rapidly growing bioethanol industry. This work prepares a basis for the production of flexible active zein based self-standing films, coatings, or casings which can be employed for biopreservation of food. However, further studies are needed to evaluate the effectiveness and stability of antimicrobial and antioxidant activities of lysozyme and catechin in different food systems at varying $\mathrm{pH}$ and temperatures. 


\section{Acknowledgement}

This work (No. 108M353) was funded by The Scientific and Technical Research Council of Turkey (TÜBITAK). We thank the Materials Research Center and Biotechnology and Bioengineering Research and Applications Center in Izmir Institute of Technology for the generous use of their facilities.

\section{References}

Alkan, D., Aydemir, L. Y., Arcan, I., Yavuzdurmaz, H., Atabay, H. I., Ceylan, C., et al. (2011). Development of flexible antimicrobial packaging materials against Campylobacter jejuni by incorporation of gallic acid into zein-based films. Journal of Agricultural and Food Chemistry, 59(20), 11003-11010.

Appendini, P., \& Hotchkiss, J. H. (2002). Review of antimicrobial food packaging. Innovative Food Science \&' Emerging Technologies, 3(2), 113-126.

Arcan, I., \& Yemenicioglu, A. (2011). Incorporating phenolic compounds opens a new perspective to use zein films as flexible bioactive packaging materials. Food Research International, 44, 550-556.

ASTM (2002). Standard test method for tensile properties of thin plastic sheetingD882-02. In ASTM (Ed.), Annual Book of American Standard Testing Methods. Philadelphia, PA.

Barth, A. (2007). Infrared spectroscopy of proteins. Biochimica et Biophysica Acta (BBA) Bioenergetics, 1767(9), 1073-1101.

Bezemer, J. M., Radersma, R., Grijpma, D. W., Dijkstra, P. J., Feijen, J., \& van Blitterswijk, C. A. (2000). Zero-order release of lysozyme from poly(ethylene glycol) poly(butylene terephthalate) matrices. Journal of Controlled Release, 64(1-3), 179-192.

Buonocore, G. G., Conte, A., Corbo, M. R., Sinigaglia, M., \& Del Nobile, M. A. (2005). Mono- and multilaver active films containing lysozyme as antimicrobial agent. Innovative Food Science \&' Emerging Technologies, 6(4), 459-464.

Chick, J., \& Hernandez, R. J. (2002). Physical, thermal, and barrier characterization of casein-wax-based edible films. Journal of Food Science, 67(3), 1073-1079.

Duan, J., Park, S. L., Daeschel, M. A., \& Zhao, Y. (2007). Antimicrobial chitosan-lysozyme (CL) films and coatings for enhancing microbial safety of Mozzarella cheese. Journal of Food Science, 72(9), M355-M362.

Fabra, M. J., Talens, P., \& Chiralt, A. (2008). Tensile properties and water vapor permeability of sodium caseinate films containing oleic acid-beeswax mixtures. Journal of Food Engineering, 85(3), 393-400.

Gemili, S., Yemenicioglu, A., \& Altinkaya, S. A. (2009). Development of cellulose acetate based antimicrobial food packaging materials for controlled release of lysozyme. Journal of Food Engineering, 90(4), 453-462.

Gucbilmez, C. M., Yemenicioglu, A., \& Arslanoglu, A. (2007). Antimicrobial and antioxidant activity of edible zein films incorporated with lysozyme, albumin proteins and disodium EDTA. Food Research International, 40(1), 80-91.

Guo, Y. C., Liu, Z. D., An, H. J., Li, M. Q., \& Hu, J. (2005). Nano-structure and properties of maize zein studied by atomic force microscopy. Journal of Cereal Science, 41(3), $277-281$.

Han, J. H. (2005). Antimicrobial packaging systems. In H. H. Jung (Ed.), Innovations in Food Packaging (pp. 80-108). London: Academic Press.

Hasni, I., Bourassa, P., Hamdani, S., Samson, G., Carpentier, R., \& Tajmir-Riahi, H. -A. (2011). Interaction of milk $\alpha$ - and $\beta$-caseins with tea polyphenols. Food Chemistry, 126(2), 630-639.

He, L., Mu, C., Shi, J., Zhang, Q., Shi, B., \& Lin, W. (2011). Modification of collagen with a natural cross-linker, procyanidin. International Journal of Biological Macromolecules, 48(2), 354-359.

Joerger, R. D. (2007). Antimicrobial films for food applications: A quantitative analysis of their effectiveness. Packaging Technology and Science, 20(4), 231-273.

Ku, K. -J., Hong, Y. -H., \& Song, K. B. (2008). Mechanical properties of a Gelidium corneum edible film containing catechin and its application in sausages. Journal of Food Science, 73(3), C217-C221.
Manley, R. H., \& Evans, C. D. (1943). Binary solvents for zein. Industrial and Engineering Chemistry, 35(6), 661-665.

Mastromatteo, M., Mastromatteo, M., Conte, A., \& Del Nobile, M. A. (2010). Advances in controlled release devices for food packaging applications. Trends in Food Science $\mathcal{E}$ Technology, 21(12), 591-598.

Mecitoglu, Ç., Yemenicioglu, A., Arslanoglu, A., Elmacl, Z. S., Korel, F., \& Çetin, A. E. (2006). Incorporation of partially purified hen egg white lysozyme into zein films for antimicrobial food packaging. Food Research International, 39(1), 12-21.

Mendes de Souza, P., Fernández, A., López-Carballo, G., Gavara, R., \& Hernández-Muñoz, P. (2010). Modified sodium caseinate films as releasing carriers of lysozyme. Food Hydrocolloids, 24(4), 300-306.

Meyers, K. J., Watkins, C. B., Pritts, M. P., \& Liu, R. H. (2003). Antioxidant and antiproliferative activities of strawberries. Journal of Agricultural and Food Chemistry, 51(23), 6887-6892.

Min, S., Harris, L. J., Han, J. H., \& Krochta, J. M. (2005). Listeria monocytogenes inhibition by whey protein films and coatings incorporating lysozyme. Journal of Food Protection, 68(11), 2317-2325.

Mohammed-Ziegler, I., \& Billes, F. (2002). Vibrational spectroscopic calculations on pyrogallol and gallic acid. Journal of Molecular Structure (THEOCHEM), 618(3), 259-265.

Ouattara, B., Simard, R. E., Piette, G., Begin, A., \& Holley, R. A. (2000). Diffusion of acetic and propionic acids from chitosan-based antimicrobial packaging films. Journal of Food Science, 65(5), 768-773.

Ozdemir, M., \& Floros, J. D. (2003). Film composition effects on diffusion of potassium sorbate through whey protein films. Journal of Food Science, 68(2), 511-516.

Padgett, T., Han, I. Y., \& Dawson, P. L. (1998). Incorporation of food-grade antimicrobial compounds into biodegradable packaging films. Journal of Food Protection, 61, 1330-1335.

Park, S. I., Daeschel, M. A., \& Zhao, Y. (2004). Functional Properties of Antimicrobial Lysozyme-Chitosan Composite Films. Journal of Food Science, 69(8), M215-M221.

Ramos-Tejada, M. M., Durán, J. D. G., Ontiveros-Ortega, A., Espinosa-Jimenez, M. Perea-Carpio, R., \& Chibowski, E. (2002). Investigation of alumina/(+)-catechin system properties. Part I: a study of the system by FTIR-UV-Vis spectroscopy. Colloids and Surfaces. B, Biointerfaces, 24(3-4), 297-308.

Re, R., Pellegrini, N., Proteggente, A., Pannala, A., Yang, M., \& Rice-Evans, C. (1999). Antioxidant activity applying an improved ABTS radical cation decolorization assay. Free Radical Biology E Medicine, 26(9-10), 1231-1237.

Robb, C. S., Geldart, S. E., Seelenbinder, J. A., \& Brown, P. R. (2002). Analysis of green tea constituents by HPLC-FTIR. Journal of Liquid Chromatography and Related Technologies, 25(5), 787-801.

Selling, G. W., Woods, K. K., Sessa, D., \& Biswas, A. (2008). Electrospun zein fibers using glutaraldehyde as the crosslinking reagent: Effect of time and temperature. Macromolecular Chemistry and Physics, 209(10), 1003-1011.

Shukla, R., \& Cheryan, M. (2001). Zein: the industrial protein from corn. Industrial Crops and Products, 13(3), 171-192.

Sohail, S. S., Wang, B., Biswas, M. A. S., \& Oh, J. -H. (2006). Physical, morphological, and barrier properties of edible casein films with wax applications. Journal of Food Science, 71(4), C255-C259.

Ünalan, İ. U., Korel, F., \& Yemenicioğlu, A. (2011). Active packaging of ground beef patties by edible zein films incorporated with partially purified lysozyme and Na2EDTA. International Journal of Food Science and Technology, 46(6), 1289-1295.

Wang, H. -J., Gong, S. -J., Lin, Z. -X., Fu, J. -X., Xue, S. -T., Huang, J. -C., et al. (2007). In vivo biocompatibility and mechanical properties of porous zein scaffolds. Biomaterials, 28(27), 3952-3964.

Wang, Q., Yin, L. L., \& Padua, G. W. (2008). Effect of hydrophilic and lipophilic compounds on zein microstructures. Food Biophysics, 3(2), 174-181.

Zhang, B., Luo, Y., \& Wang, O. (2011). Effect of acid and base treatments on structural, rheological, and antioxidant properties of $\alpha$-zein. Food Chemistry, 124(1), 210-220.

Zou, T., Li, Z., Percival, S. S., Bonard, S., \& Gu, L. (2012). Fabrication, characterization, and cytotoxicity evaluation of cranberry procyanidins-zein nanoparticles. Food Hydrocolloids, 27(2), 293-300. 